\title{
Effects of Calcium Antagonists on a-Adrenoceptor Mediated Vasoconstrictions of the Canine Intermediate Auricular Artery
}

\author{
Takashi ITO and Shigetoshi CHIBA*,** \\ Department of Dermatology and *Department of Pharmacology. \\ Shinshu University School of Medicine, 390 Matsumoto. Japan
}

Accepted February 16, 1987

\begin{abstract}
The effects of calcium antagonists, diltiazem (DI) and verapamil (VE). on $\alpha$-adrenoceptor-mediated contractile responses of the isolated and perfused canine intermediate aulicular artery were examined by use of the stainless steel cannula inserting method. $\mathrm{KCl}(3 \mathrm{mg}$ )-induced contractile responses were dosedependently inhibited by $\mathrm{Dl}$ and VE. Norepinephrine $(0.1 \mu \mathrm{g})$-induced vasoconstrictions were also dose-dependently inhibited by both DI and VE. DI and $V E$ shifted dose-response curves for phenylephrine and clonidine to the right with suppiession of maximal responses. At large doses. DI and VE suppressed clonidineinduced contractions more than phenvlephrine-induced ones, but not significantly. It is concluded that 1) not oniy $\alpha_{1}$ - but also $\alpha_{2}$-adrenoceptor mediated vasoconstrictions of the canine intermediate auricular artery are dependent on the influx of extracellular calcium ions, 2) the present results may provide in vitro proof for the effectiveness of calcium antagonists on skin circulatory disturbances such as Raynaud's phenomenon and 3) the isolated and perfused canine intermediate auricular artery would be a good in vitro model for investigating responsiveness of the skin supplying artery
\end{abstract}

Calcium antagonists are widely used in the treatment of coronary diseases and hypertension (1). They are thought to bring vasodilatations through blocking the entry of extracellular calcium ions into vascular smooth muscle cells (2). Recently, in dermatology-associated fields. calcium antagonists have been used in treatments of peripheral circulatory disturbances such as Raynaud's phenomenon (3-6). It seems reasonable that calcium antagonists are effective on skin vasospastic diseases because of their properties to inhibit catecholamine-induced vasoconstrictions $(7,8)$. However, it is reported that calcium antagonists do not act similarly on catecholamine-induced constrictions of various vasculatures but have vascular selectivity (9), and there are few experimental articles available on the in vitro effect of calcium antagonists on the skin supplying arteries (10). We previously

* To whom correspondence should be addressed. reported that the canine intermediate auricular artery, which supplies blood flow mainly to the skin of the ear, represents very similar vascular responsiveness to the human digital artery (11). In the present study, we attempted provide in vitro proof for the inhibiting effects of calcium antagonists on catecholamine-induced vasoconstrictions of skin arteries by use of the isolated and perfused canine intermediate auricular artery.

\section{Materials and Methods}

Arterial preparations: Mongrel dogs of either sex $(6-18 \mathrm{~kg})$ were anesthetized with sodium pentobarbital ( $30 \mathrm{mg} / \mathrm{kg}$. i.v.). After treatment with sodium heparin (200 units/ $\mathrm{kg}$, i.v.), the dogs were sacrificed by rapid exsanguination from the right common carotid artery. The intermediate auricular artery of either ear was then carefully isolated, and 1-3 segments (without large branches, $0.4-0.7 \mathrm{~mm}$ in outer diameter, $4-7 \mathrm{~mm}$ in length) were cut from each isolated artery. 
Each segment was inserted with a stainlesssteel cannula with one small hole at $3 \mathrm{~mm}$ distance from the distal blind end (27 gauge. $0.4 \mathrm{~mm}$ in outer diameter and $3 \mathrm{~cm}$ in length). The arterial segment was tied to the cannula distal to the hole. and thus the stream from the hole of the cannula passes only through the endothelial surface of the vascular segment (12). The cannulation procedure was performed in cold Ringer's solution at a temperature of $4-10^{\circ} \mathrm{C}$; attention was paid to avoid endothelial damage, although we can not absolutely negate the possibility that the inserting cannula may have caused some functional disturbance of the endothelium. The stainless steel cannula and the arterial preparation were placed in a cup shaped glass container and perfused with constant flow by means of a peristaltic pump (Harvard Apparatus, Model 505-1210). The perfusate contained $(\mathrm{mM}) \mathrm{NaCl}, 118 ; \mathrm{KCl}, 4.7$; $\mathrm{KH}_{2} \mathrm{PO}_{4}, 1.3 ; \mathrm{MgCl}_{2}, 1.2 ; \mathrm{CaCl}_{2}, 2.5$; $\mathrm{NaHCO}_{3}, 25$ and glucose, 5.6, and it was bubbled with a mixture of $95 \% \mathrm{O}_{2}$ and $5 \%$ $\mathrm{CO}_{2}$ to maintain the $\mathrm{pH}$ at $7.2-7.4$ and was maintained at a constant temperature of $37^{\circ} \mathrm{C}$. The glass container was also warmed with a circulator pump (Haake) at a constant temperature of $37^{\circ} \mathrm{C}$. The flow rate $(1-2 \mathrm{ml} /$ min) was adjusted at the beginning of the experiment to obtain a basal perfusion pressure of approximately $100 \mathrm{mmHg}$. The perfusion pressure was measured with an electronic manometer (Nihon Kohden, RP 2 ), and a vasoconstriction was recorded as an increase in perfusion pressure. Before the experiments were started, the preparations were allowed to equilibrate for over $1 \mathrm{hr}$ in the bathing medium.

Dose-response curves and effects of calcium antagonists: To determine the doseresponse curves, increasing doses of each agent were injected at $3-6$ min intervals. The effects of calcium antagonists were examined by determining dose-response curves after bolus injections of increasing doses of each calcium antagonist or comparing responses induced by the same dose of agent before and after a bolus injection of increasing doses of each calcium antagonist.

Drugs: Drugs used were dl-norepinephrine hydrochloride (NE, Sankyo), phenyleph- rine hydrochloride (PE, Kowa), clonidine hydrochloride (CL, Boehringer-Ingelheim), diltiazem hydrochloride (Dl, Tanabe), verapamil hydrochloride (VE, Eisai) and potassium chloride $(\mathrm{KCl})$. Drugs were dissolved in $0.9 \%$ saline. All drug solutions were bolusly injected by a microinjector (Terumo) into the rubber tubing close to the cannula in a volume of $0.01-0.03 \mathrm{ml}$.

Data analysis: The data are shown as the means \pm S.E.M. Statistical differences between two means were determined by Student's $t$-test for unpaired observations.

\section{Results}

$\mathrm{KCl}$-induced vasoconstrictions: To ascertain that calcium antagonists act really as a calcium entry blocker in the present experimental model, the effects of DI and VE on $\mathrm{KCl}$-induced vasoconstrictions were examined. The injection of $3 \mathrm{mg}$ of $\mathrm{KCl}$ produced a transient contractile response. and the actual increase in perfusion pressure was $78.3 \pm 12.2 \mathrm{mmHg}$ (mean \pm S.E.M., $\mathrm{n}=8$ ). DI and VE suppressed $\mathrm{KCl}$-induced vaso-

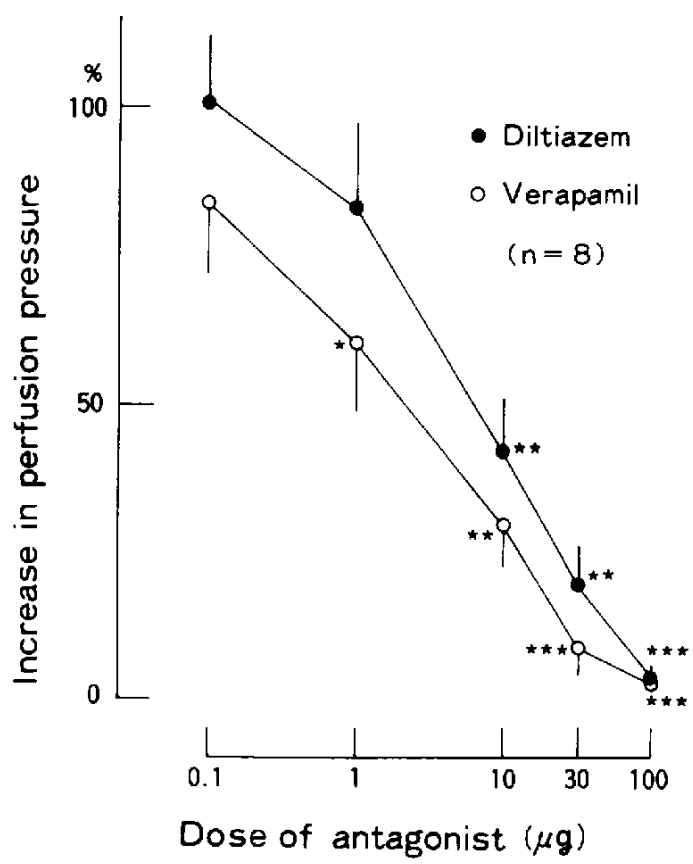

Fig. 1. Effects of calcium antagonists on $\mathrm{KCl}$ (3 $\mathrm{mg}$ )-induced vasoconstrictions of the canine intermediate auricular artery. Values represent the means \pm S.E.M. ( $\left.P<0.05,{ }^{* *} P<0.01,{ }^{* * *} P<0.001\right)$. 
constrictions in a dose-related manner, and the potencies of both agents were not much different: i.e., at the dose of 0.1 or $1 \mu \mathrm{g}$. DI revealed a more potent tendency to suppress the $\mathrm{KCl}$-induced response (statistically not significant), but at larger doses, there were no differences between the effects of DI and VE (Fig. 1).

NE-induced vasoconstrictions: The injection of $0.1 \mu \mathrm{g}$ of $\mathrm{NE}$ produced an increase in $148.6 \pm 30.3 \mathrm{mmHg}$ in perfusion pressure $(n=8)$. DI and VE suppressed NE-induced responses in a dose-dependent manner, and the potencies of both calcium antagonists were almost the same (Fig. 2).

PE-induced vasoconstrictions: PE produced transient contractile responses in a dose-dependent manner. Effects of $D \mid$ and $V E$ on the dose-response curve for $P E$ are shown in Figs. 3 and 4, respectively. In the control, the threshold dose of PE for producing a contractile response was 0.003-

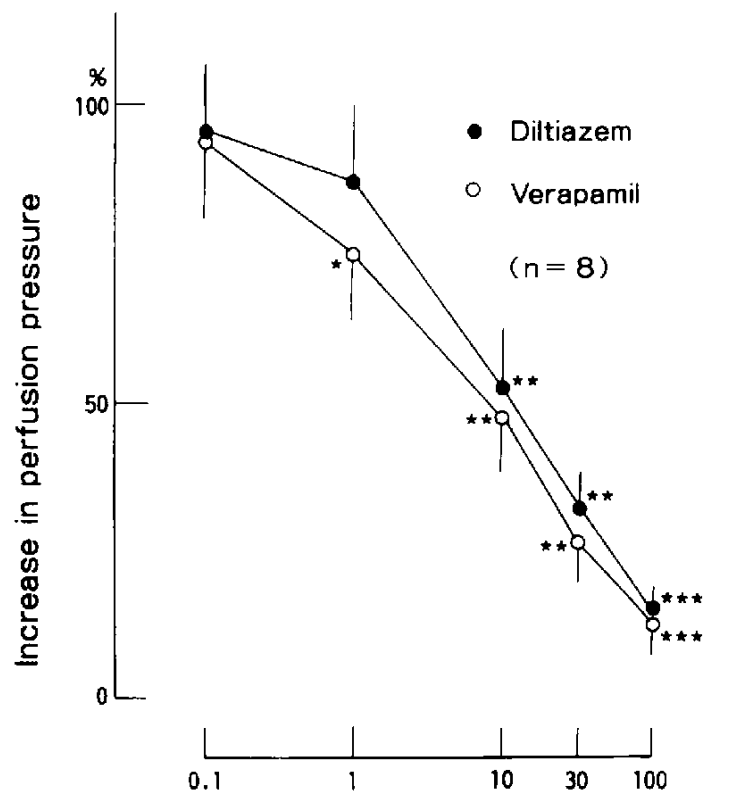

Dose of antagonist $(\mu \mathrm{g})$

Fig. 2. Effects of calcium antagonists on norepinephrine $(0.1, \mu \mathrm{g})$-induced vasoconstrictions of the canine intermediate auricular artery. Values represent the means \pm S.E.M. * "**, ***: Significantly different from each control $\left({ }^{*} P<0.05\right.$. ${ }^{*} P<0.01$. ***P<0.001).
$0.01 \% \mathrm{~g}$. and $0.3-1 \mathrm{~kg}$ of PE caused an increase in perfusion pressure of about 200 $\mathrm{mmHg}$. DI shifted the dose-response curve to the right in a dose-dependent manner. Pretreatments with $1-10 \mathrm{~kg}$ of $\mathrm{D} /$ revealed a parallel shift of the dose-response curve for $P E$, but with 30-100 $/ \mathrm{g}$ of $\mathrm{Dl}$, the maximal response was suppressed. VE also dosedependently shifted the dose-response curve for $P E$ to the right roughly in a parallel fasion, but the maximal response was readily sup. pressed by $10 \mu \mathrm{g}$ or more of $\mathrm{VE}$.

Clonidine-induced vasoconstrictions: $\mathrm{Clo}$ nidine also caused dose-dependent contractile responses, i.e.. the threshold dose for inducing vasoconstrictions was about 0.003 $\mu \mathrm{g}$. and $0.1-0.3 \mu \mathrm{g}$ of $\mathrm{Cl}$ produced an approximately $200 \mathrm{mmHg}$ increase in perfusion pressure. Small doses of DI and VE shifted the dose-response curve for $\mathrm{CL}$ parallel to the right. Large doses of $\mathrm{DI}$ and VE suppressed the maximal response to $\mathrm{CL}$ (Figs. 5 and 6 ) to a much greater extent than that to PE (Figs. 3 and 4).

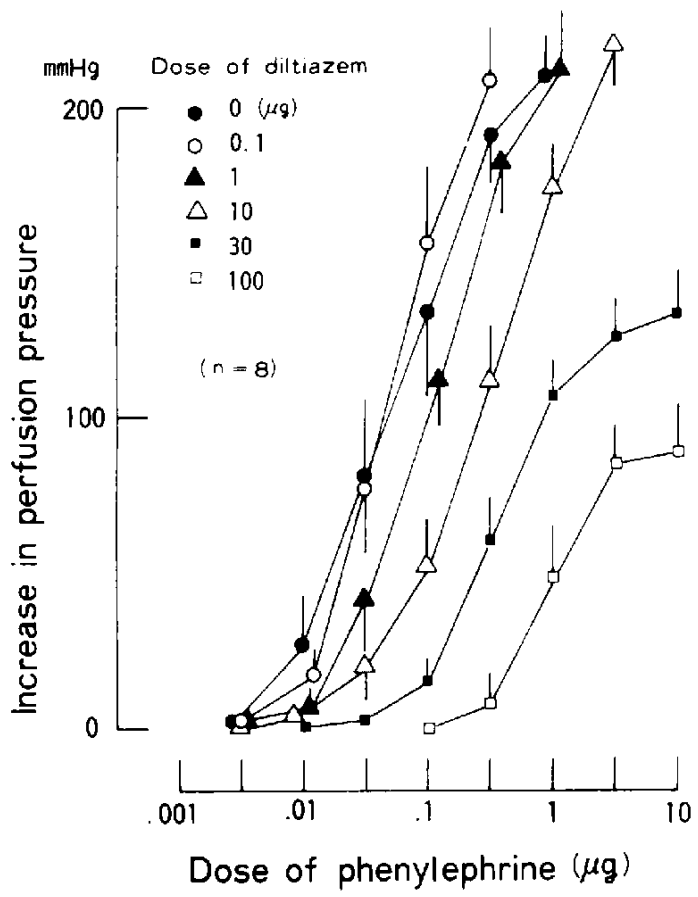

Fig. 3. Effects of diltiazem on the dose-response curve for phenylephrine of the canine intermediate auricular artery. Values represent the means \pm S.E.M. 


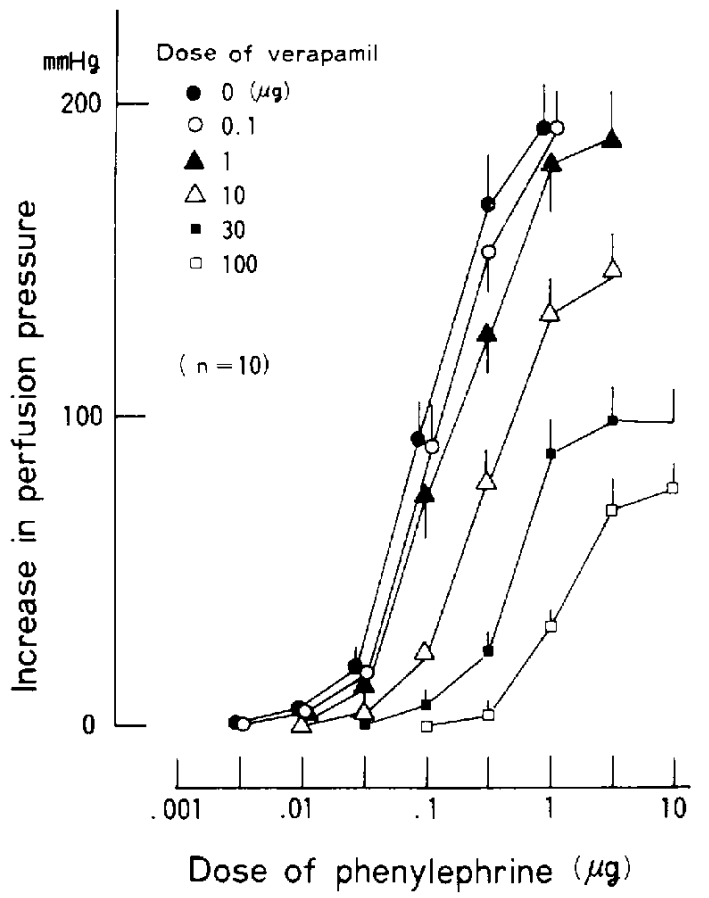

Fig. 4. Effects of verapamil on the dose-response curve for phenylephrine of the canine intermediate auricular artery. Values represent the means \pm S.E.M.

\section{Discussion}

Drugs that have antihypertensive or vascular relaxing properties are frequently used in the treatment of Raynaud's phenomenon (13-15). Calcium antagonists are included among these drugs, but their clinical efficacy on Raynaud's phenomenon has not been established yet $(3,4)$. In the present study, we confirmed the potent inhibiting effects of DI and VE on the druginduced vasoconstriction of the isolated and perfused canine intermediate auricular artery. This vessel. with a larger diameter than arterioles, belongs to one of the subcutaneous arteries; and in strict sense, it does not control the cutaneous circulation which is directly controlled by cutaneous microvasculatures. It has been, however, reported that relatively larger arteries with diameters of $100-400 \mu \mathrm{m}$ can constrict sufficiently to provide considerable resistence (16); and since the canine intermediate auricular artery is thought to be a good model for the

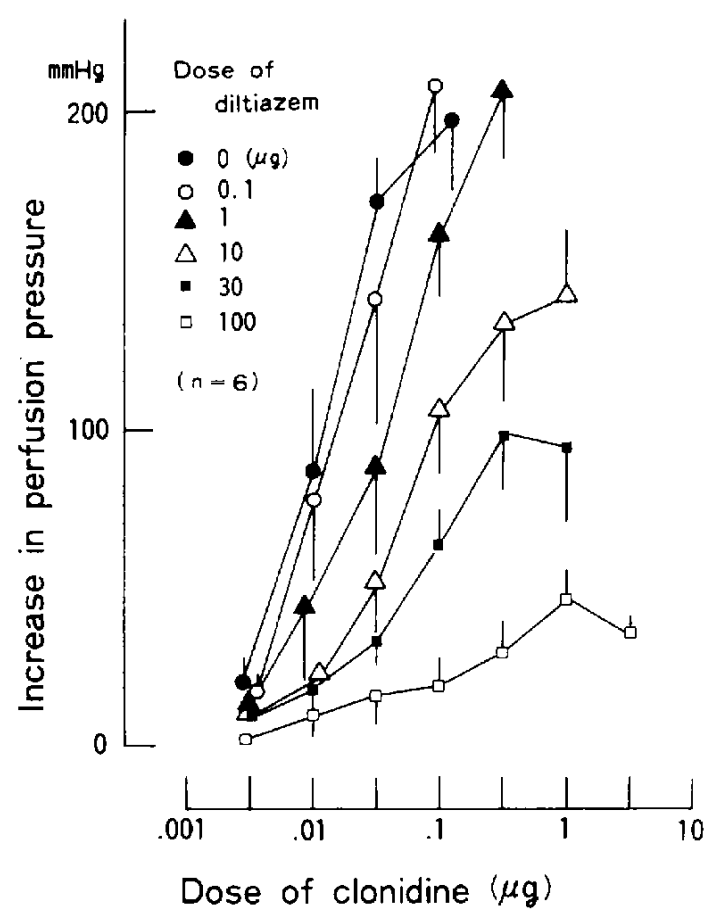

Fig. 5. Effects of dittazem on the dose-response curve for clonidine of the canine intermediate auricular artery. Values represent the means \pm S.E.M.

study of the skin supplying arteries (17-19). the results from present examinations would give an in vitro experimental basis for the possible efficacy of calcium antagonists in skin vasospastic diseases like Raynaud's phenomenon. Another point of interest in the present study is the relationship of $\alpha$ adrenoceptor subtypes and effects of calcium antagonists. It is widely accepted that vascular postsynaptic $\alpha$-adrenoceptors are divided into two subtypes, namely $\alpha_{1}$ - and $\alpha_{2}$-adrenoceptors (20). In general, postsynaptic $\alpha_{1}$-adrenoceptors are dominant in vascular smooth muscles as reviewed by Starke (20). Previously, we demonstrated that there were rich postsynaptic $\alpha_{1}-$ and $\alpha_{2}-$ adrenoceptors in the canine intermediate auricular artery because PE (an $\alpha_{1}$-adrenoceptor agonist) had almost the same potency and efficacy as xylazine or CL $\left(\alpha_{2}-\right.$ adrenoceptor agonists) (21). In this study. calcium antagonists inhibited not only $\mathrm{KCl}$ but also NE-induced vasoconstrictions. Since NE-induced constrictions in large arteries 


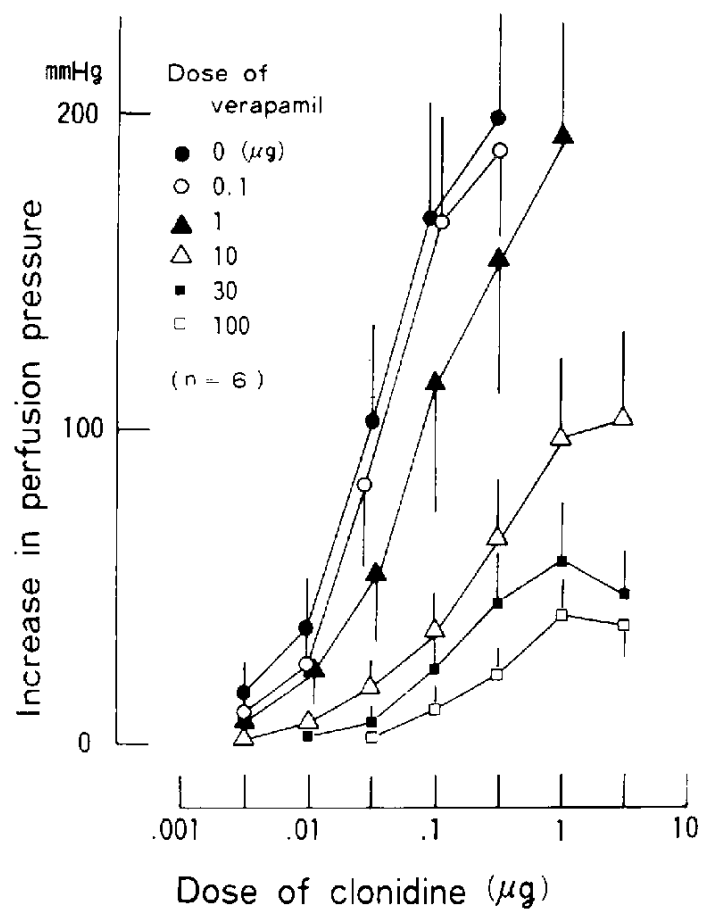

Fig. 6. Effect of verapamil on the dose-response curve for clonidine of the canine intermediate auricular artery. Values represent the means \pm S.E.M.

are usually resistant to calcium antagonists (22), extracellular calcium ions might not have an important role in such vessels. However, in this intermediate auricular artery, extracellular calcium ions may have an important role in the production of a constriction. In Ca-free solution. $\mathrm{KCl}$ induced vasoconstriction was completely abolished and NE-induced constriction was markedly suppressed in 2 experiments (data not shown). It has been reported that $\alpha_{2}-$ adrenoceptor-mediated vasoconstrictions are sensitive to calcium antagonists, whereas $\alpha_{1}$ adrenoceptor-mediated ones are resistant (23. 24). In this study, with relatively small doses, both calcium antagonists suppressed either CL- or PE-induced vasoconstrictions. However, a relative large dose of calcium antagonists depressed CL-induced responses more than PE-induced ones, but not significantly. Thus, it is stil! difficult to prove that calcium antagonists are sensitive to $\alpha_{1}$ adrenoceptors in this study.

The canine intermediate auricular artery used in the present experiments had a diameter of $400-700 \mu \mathrm{m}$, which slightly exceeded the diameter of so-called resistance vessels (25). Therefore, a possible explanation for the present results is that the canine intermediate auricular artery has the same properties as resistance vessels. It is also suggested that $\alpha$-adrenoceptors of the human digital artery might be atypical and might not be classified into ordinary $\alpha_{1}$ - or $\alpha_{2}$-adrenoceptors (26), and we also reported that the canine intermediate auricular artery might have such atypical $\alpha$-adrenoceptors (21). The present results that PE-induced vasoconstriction was readily suppressed by calcium antagonists might be supporting evidence for the existence of atypical $\alpha$ adrenoceptors in the canine intermediate auricular artery. A relatively small dose of diltiazem rather enhanced phenylephrineinduced constriction, but not significantly. This is no clear explanation for potentiating effect of diltiazem. We recently, using the same method in the present study, reported that the simian digital artery shows similar responsiveness to the canine intermediate auricular artery and might have functional $\alpha_{2}$-adrenoceptors (27). The common property of the human digital, simian digital and canine intermediate auricular arteries is that they are all skin supplying arteries and that digital and ear skins are areas with rich arterio-venous anastomosis. From the dermatological aspects, fingers and ears are common sites affected in various diseases such as systemic lupus erythematosus, progressive systemic sclerosis or cold injury. On these bases, we believe that the isolated and perfused canine intermediate auricular artery may be a good model for in vitro study of skin vasculatures.

\section{References}

1 Stone, P.H., Antman, E.N., Muller, J.E. and Braunwald, E.: Calcium channel blocking agents in the treatment of cardiovascular disorders. Part 11: Hemodynamic effects and clinical applications. Ann. Intern. Med. 93, 886-906 (1980)

2 Vanhoutte, P.M.: Calcium-entry blockers and vascular smooth muscle. Circulation 65, s11s19(1982)

3 Kinney, E.L., Nicholas, G.G., Gallo, J., Pon- 
toriero, C. and Zelis, R.: The treatment of severe Raynaud's phenomenon with verapamil. J. Clin. Pharmacol. 22, 74-76 (1982)

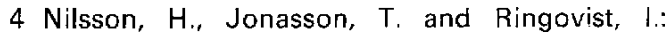
Treatment of digital vasospastic disease with the calcium-entry blocker nifedipine. Acta Med. Scand. 215, 135-139 (1984)

5 Smith, C.D. and McKendy, R.J.R.: Controlled trial of nifedipine in the treatment of Raynaud's phenomenon. Lancet 2, 1299-1301 (1982)

6 Vayssairat, M.: Calcium channel blockers and Raynaud's disease. Ann. Intern. Med. 95, 243 (1981)

7 Daniel, E.E.: Cellular calcium mobilization. J. Cardiovasc. Pharmacol. 6, s622-s629 (1984)

8 Folkow, B., Hallback, M., Jones, J.V. and Sutter, M.: Dependence on external calcium for the noradrenaline contractility of the resistance vessels in spontaneously hypertensive and renal hypertensive rats, as compared with normotensive controls. Acta Physiol. Scand. 101, 84-97 (1977)

9 Cauvin, C., Lukeman, S., Cameron, J., Hwang, O., Meisheri, K., Yamamoto, $H$. and van Breemen, C.: Theoretical bases for vascular selectivity of $\mathrm{Ca}^{2+}$ antagonists. J. Cardiovasc. Pharmacol. 6, s630-s638 (1984)

10 Jauernig, R.A. and Moulds, R.F.W.: A human arterial preparation for studying the effects of vasoactive agents. Circ. Res. 42, 363-368 (1978)

11 Ito, T and Chiba, S.: Vascular responsiveness of isolated canine intermediate auricular artery to vasoactive substances. Arch. Int. Pharmacodyn. Ther. 268, 225-231 (1984)

12 Tsuji, T. and Chiba, S.: Potentiating effect of methysergide on norepinephrine-induced constriction of the isolated internal carotid artery of the dog. Japan. J. Pharmacol. 34, 95-100 (1984)

13 Roald, O.K. and Seem, E.: Treatment of Raynaud's phenomenon with ketanserin in patients with connective tissue disorders. Br. Med. J. 289, 577-579 (1984)

14 Surwit, R.S., Gligor, R.S., Allen, L.M. and Duvic, M.: A double-blind study of prazosin in the treatment of Raynaud's phenomenon in scleroderma. Arch. Dermatol. 120, 329-311 (1984)
15 Surwit, R.S., Gligor, R.S., Duvic, M., Allen, L.M. and Neal, J.A.: Intra-arterial reserpine for Raynaud's syndrome. Arch. Dermatol, 119, 733735 (1983)

16 Haddy, F.J.: Local effect of sodium, calcium and magnesium upon small and large blood vessels of the dog forelimb. Circ. Res. 8, 57-71 (1960)

17 Chiba, S. and Ito, T.: Predominant sensitivity to tyramine in canine intermediate auricular artery. J. Auton. Pharmacol. 5, 109-114 (1985)

18 Ito, T. and Chiba, S.: Responses of isolated canine intermediate auricular artery to 5-hydroxytryptamine and methysergide. Eur. J. Pharmacol. 104, 105-109 (1984)

19 Sams, W.M. and Winkelman, R.K.: Effect of corticosteroids on isolated vascular smooth muscle. J. Invest. Dermatol. 49, 519-525 (1967)

20 Starke, K.: $\alpha$-Adrenoceptor subclassification. Rev. Physiol. Biochem. Pharmacol. 88, 199-236 (1981)

21 Ito, T. and Chiba, S.: Existence of two types of postjunctional alpha adrenoceptors in the isolated canine intermediate auricular artery. J. Pharmacol. Exp. Ther. 234, 698-702 (1985)

22 Vanhoutte, P.M.: Heterogeneity of postjunctional vascular $\alpha$-adrenoceptors and handling of calcium. J. Cardiovasc. Pharmacol. 4, \$91-\$96 (1982)

23 Van Zwieten, P.A., van Meel, J.C.A., de Jong, A., Wilffert, B. and Timmermans, P.B.M.W.M.: Central and peripheral $\alpha$-adrenoceptors. J. Cardiovasc. Pharmacol. 4, s19-s24 (1983)

24 Van Zwieten, P.A., van Meel, J.C.A. and Timmermans, P.B.M.W.M.: Calcium antagonists and $\alpha_{2}$-adrenoceptors: possible role of extracellular calcium ions in $\alpha_{2}$-adrenoceptormediated vasoconstriction. J. Cardiovasc. Pharmacol. 4, s273-s279 (1982)

25 Verstraete, M.: Precapillary vessels and peripheral vascular ischemic disease. J. Cardiovasc. Pharmacol. 6, s720-s724 (1984)

26 Stevens, M.J. and Moulds, R.F.: Are the preand postsynaptic $\alpha$-adrenoceptors in human vascular smooth muscle atypical? J. Cardiovasc. Pharmacol. 4, si 29-s133 (1982)

27 Ito, T. and Chiba, S.: Vascular responsiveness of simian digital artery to various vasoactive substances. J. Invest. Dermatol. 86, 678-682 (1986) 